\title{
Problems with bleep use: Are smartphone group messaging services the answer?
}

\author{
Ali Adel Ne'ma Abdullah ${ }^{1}$, Katie Wright ${ }^{2}$, Annabelle Lochrane ${ }^{2}$ and Hasan Haboubi ${ }^{3 *}$ \\ ${ }^{1}$ University Hospital of Wales, Cardiff, UK \\ ${ }^{2}$ Singleton Hospital, Sketty Ln, Sketty, UK \\ ${ }^{3}$ Swansea University School of Medicine, Institute of Life Science 2, UK
}

\begin{abstract}
Introduction: Evidence suggests that doctors find bleeps frustrating. This study aimed to quantify specific difficulties and explore perceptions and usage of WhatsApp as an alternative.

Methods: A 13-question online questionnaire was sent to doctors of a small district general hospital interrogating use of WhatsApp and reasons behind its favoured use compared to a bleep system.

Results: Issues with bleep use included no answer to bleeps, phone engaged and unable to find a phone to answer bleeps. Foundation doctors generally encountered these problems the most, especially with no answer to bleeps ( $\mathrm{p}=0.047)$ and inability to find a phone $(\mathrm{p}=0.032)$.

Work-related WhatsApp usage was prevalent, mainly for intra-team communication, with foundation doctors using it the most ( $\mathrm{p}=0.057$ ). Doctors who experienced the most issues with bleeps tended to use WhatsApp more ( $\mathrm{p}=0.007)$.

Discussion: Bleeps are widely disliked amongst medical professionals who are increasingly using platforms such as WhatsApp. Our study has identified a number of potential reasons for this. Unless a solution is implemented, usage of such platforms will only increase despite concerns regarding patient confidentiality.
\end{abstract}

\section{Introduction}

Smartphones are highly advanced technological devices that have become an increasingly pervasive part of our lives [1]. Medical fields are no exception and have largely warmly welcomed the advent of smartphones and portable digital technology, utilising them for patient monitoring, diagnostics and medical education [2].

Communication in medicine is of paramount importance. Intraand inter-team communication is used to seek advice about unwell patients, gain more information about their background or refer them elsewhere. It is one of the fundamental tenets of the General Medical Council's (GMC) Good Medical Practice.

For communication purposes hospitals in the UK largely remain reliant upon the well-established system of bleeps. Bleeps are radio boxes that bleep when someone is trying to contact. The receiver is then obliged call back, usually by locating a hospital phone or from their personal mobiles [3]. This provides one-way communication only, and evidence suggests that some doctors find this system frustrating [4]. Literature on reasons for this include that bleeping someone is slower than using a mobile phone, mobile phones are more convenient, mobile phones allow instant messages to multiple recipients [5], mobile phones allow transmittance of radiological images [6,7], people take too long to answer bleeps, the phone is often engaged when replying and that it interrupts ward duties more than using a mobile [3].

This study aimed to quantify the specific difficulties experienced by doctors using the bleep system, as well as explore their perceptions and usage of smartphones as an alternative means of intra- and interteam communication. We chose to focus on the use of WhatsApp, an incredibly popular encrypted messaging platform with a reported userbase exceeding 1.5 billion worldwide. This application was recently evaluated in a large systematic review which identified 30 studies investigating the use of WhatsApp [8]. The pooled data showed compelling evidence that the WhatsApp messenger system offered promise in both inter-professional communication as well as its potential for communication with patients.

\section{Methods}

A structured questionnaire consisting of 13 questions was sent to doctors working in Singleton Hospital, a District General Hospital in Swansea, Wales, UK covering a population of over 240,000 people. Within this hospital all grades of doctors, including consultants can carry bleeps and as such allowed for a full evaluation of bleep use across different levels of seniority.

These doctors were emailed a link to an online questionnaire with a reminder email sent at 2 weeks. The questionnaire was open to complete for a total of 4 weeks.

Questions enquired into use of the bleep, difficulties experienced with it and use of group messaging services as an alternative method

${ }^{\star}$ Correspondence to: Hasan Haboubi, Swansea University School of Medicine, UK. E-mail: hasanhaboubi@doctors.org.uk

Key words: communication, bleeps, smartphone applications

Received: October 13, 2019; Accepted: November 22, 2019; Published: November 27, 2019 
of communication. The scope of the study was deliberately focussed on doctors and their use of WhatsApp when compared to bleeps, and to evaluate if there were any differences in perspectives between junior and senior members.

Ethical approval was sought from and approved by the Abertawe Bro Morgannwg Audit and Research Department.

The data was tested for normality using the Shapiro Wilks Test and subsequent statistical calculations were performed with nonparametric tests using the Statistical Package for the Social Sciences (SPSS 23.0, IBM Corp., Armonk, New York, USA).

\section{Results}

\section{Demographics}

A total of 208 doctors were contacted via email with 53 doctors fully completing the questionnaire ( 25 male, 28 female) giving a response rate of $25.5 \%$.

A total of $43 \%$ of respondents were Foundation Year $1(23 / 53)$ doctors, 6\% Foundation Year 2 doctors (3/53), 15\% Core Trainees (8/53), 25\% Specialist Trainees (13/53), 9\% Consultants (5/53) and 2\% Associate Specialists (1/53). Of those who completed the questionnaire, a total of $51 \%$ of doctors were working in medical specialities (27/53), $32 \%$ in surgical specialities $(17 / 53)$ and $17 \%$ in acute specialties, i.e. A\&E/Acute Medicine/Anaesthetics/ITU (9/53).

\section{Grievances with bleep use}

We interrogated perceived issues with bleep use. The vast majority of the doctors questioned stated that they sometimes experience no answers to their bleeps on trying to respond to a call, whilst only $9.4 \%$ never experienced this. Foundation doctors demonstrated the greatest trouble with this (Table 1) and was statistically significant when compared to other grades ( $\mathrm{p}=0.047)$.

Upon trying to reply to a bleep, doctors of all grades stated that they often experience the phone to be engaged (frequency with which this occurred reported as $45.3 \%$ weekly, $28.3 \%$ once daily and $18.9 \%$ more than once daily). Again, this affected more junior doctors more than more senior grades, although this did not reach significance, $\mathrm{p}=0.146$.

Many doctors ( $77.4 \%$ of respondents) stated that after receiving a call on their bleep they were unable to find an available phone in which to answer a bleep causing frustration and inhibiting their work flow. Once again, this affected foundation doctors more than the other grades, $\mathrm{p}=0.032$ (Table 1 ).

\section{Work-related WhatsApp use}

In light of the problems experienced with bleeps, we investigated respondents' work-related usage of an alternative form of communication such as the smartphone communication service WhatsApp. The majority of doctors (76.3\%) confessed to usage of WhatsApp to communicate whilst at work, with a greater skew towards the younger, more junior doctors (Table 1). Female doctors $(25 / 28)$

Table 1. Summary of responses regarding issues with bleep use compared to the instant messaging application (WhatsApp)

\begin{tabular}{|c|c|c|c|c|c|}
\hline & & Foundation doctors & $\begin{array}{l}\text { Core trainees/ } \\
\text { SHO }\end{array}$ & Specialty registrars/ Consultants & p-value \\
\hline \multicolumn{6}{|l|}{ Issues with bleep use } \\
\hline - No answer to bleep & $\begin{array}{l}\text { Never } \\
\text { Weekly } \\
\text { Once Daily } \\
\text { >Once daily }\end{array}$ & $\begin{array}{c}0 \% \\
39.1 \% \\
30.4 \% \\
30.4 \%\end{array}$ & $\begin{array}{c}9 \% \\
55 \% \\
27 \% \\
9 \%\end{array}$ & $\begin{array}{c}21 \% \\
58 \% \\
21 \% \\
0 \%\end{array}$ & 0.047 \\
\hline - Phone engaged & $\begin{array}{l}\text { Never } \\
\text { Weekly } \\
\text { Once Daily } \\
\text { >Once daily }\end{array}$ & $\begin{array}{c}0 \% \\
39.1 \% \\
26.1 \% \\
34.8 \%\end{array}$ & $\begin{array}{c}9 \% \\
55 \% \\
27 \% \\
9 \%\end{array}$ & $\begin{array}{c}16 \% \\
47 \% \\
32 \% \\
5 \%\end{array}$ & 0.146 \\
\hline - Unable to find phone & $\begin{array}{l}\text { Never } \\
\text { Weekly } \\
\text { Once Daily } \\
\text { >Once daily }\end{array}$ & $\begin{array}{c}9 \% \\
26 \% \\
30 \% \\
35 \%\end{array}$ & Not used for comparison & $\begin{array}{c}37 \% \\
37 \% \\
21 \% \\
5 \% \\
\end{array}$ & 0.032 \\
\hline \multicolumn{6}{|l|}{ Work-related WhatsApp use } \\
\hline - Communication & $\begin{array}{l}\text { Yes } \\
\text { No }\end{array}$ & $\begin{array}{l}87 \% \\
13 \%\end{array}$ & $\begin{array}{l}73 \% \\
27 \%\end{array}$ & $\begin{array}{l}58 \% \\
42 \%\end{array}$ & 0.104 \\
\hline - Intra-team patient advice & $\begin{array}{l}\text { Never } \\
\text { Weekly } \\
\text { Once Daily } \\
\text { >Once daily }\end{array}$ & $\begin{array}{c}30 \% \\
13 \% \\
4 \% \\
35 \% \\
17 \%\end{array}$ & $\begin{array}{c}55 \% \\
9 \% \\
0 \% \\
0 \% \\
36 \% \\
\end{array}$ & $\begin{array}{c}68 \% \\
5 \% \\
11 \% \\
11 \% \\
5 \%\end{array}$ & 0.057 \\
\hline - Extra-team patient advice & $\begin{array}{l}\text { Never } \\
\text { Monthly } \\
\text { Weekly } \\
\text { Once Daily } \\
\text { >Once daily }\end{array}$ & $\begin{array}{c}70 \% \\
17 \% \\
4 \% \\
4 \% \\
4 \% \\
\end{array}$ & $\begin{array}{c}91 \% \\
0 \% \\
9 \% \\
0 \% \\
0 \% \\
\end{array}$ & $\begin{array}{c}100 \% \\
0 \% \\
0 \% \\
0 \% \\
0 \%\end{array}$ & 0.227 \\
\hline - Rota swaps & $\begin{array}{l}\text { Never } \\
\text { Weekly } \\
\text { Once Daily } \\
>\text { Once daily }\end{array}$ & $\begin{array}{c}26 \% \\
43 \% \\
30 \% \\
0 \%\end{array}$ & $\begin{array}{c}64 \% \\
27 \% \\
0 \% \\
9 \%\end{array}$ & $\begin{array}{c}74 \% \\
16 \% \\
5 \% \\
5 \%\end{array}$ & 0.014 \\
\hline Social-related WhatsApp use & $\begin{array}{l}\text { Never } \\
\text { Weekly } \\
\text { Monthly } \\
\text { Once Daily } \\
\text { >Once daily }\end{array}$ & \begin{tabular}{c|}
$13 \%$ \\
$4 \%$ \\
$26 \%$ \\
$26 \%$ \\
$30 \%$ \\
\end{tabular} & $\begin{array}{c}27 \% \\
9 \% \\
36 \% \\
9 \% \\
18 \% \\
\end{array}$ & $\begin{array}{l}47 \% \\
11 \% \\
11 \% \\
21 \% \\
11 \% \\
\end{array}$ & 0.248 \\
\hline WhatsApp score vs bleep & Mean (1-5) & 3.43 & 3.55 & 2.68 & 0.096 \\
\hline
\end{tabular}


were more likely to engage in work-related WhatsApp use than their male counterparts (14/25), $\mathrm{p}=0.006$.

The greatest work-related use of WhatsApp was for patient advice within the doctors' own teams. Although $49.1 \%$ never used it for this purpose, the majority (51.9\%) do with $9.4 \%$ estimating that they used the instant messaging service for this purpose monthly, 5.7\% weekly, $18.9 \%$ once daily and $17.0 \%$ more than once daily. When comparing grades of doctors who do this, statistical significance was almost achieved $(\mathrm{p}=0.057)$ with a greater skew again towards foundation doctors. Patient advice outside the doctors' teams was also sought, although this was rarer (Table 1).

Doctors who were unable to find phones to return bleeps were statistically more likely to use WhatsApp for patient advice within their own team $(\mathrm{p}=0.042)$. Similarly, doctors whose bleeps sounded at inappropriate times were more likely to use WhatsApp for this purpose $(\mathrm{p}=0.026)$.

Finally, instant messaging smartphone applications were commonly used to organise rota swaps and inform team members of illness. When comparing grades of doctors who organise rota swaps, statistical significance was achieved $(\mathrm{p}=0.014)$ with a greater skew towards the foundation doctors and core trainees. When comparing grades of doctors who inform team members of illness, statistical significance was achieved $(\mathrm{p}=0.019)$ with a greater skew towards the foundation doctors. Females (25/28) responded that they were also statistically more likely to do so than males (10/25), $\mathrm{p}=0.003$.

\section{Social-related use of WhatsApp}

The majority of doctors who responded (71.7\%) admitted to using WhatsApp as a social tool amongst colleagues whilst at work, with a reported frequency of use in this capacity of $7.5 \%$ monthly, $22.6 \%$ weekly, $20.8 \%$ once daily and $20.8 \%$ more than once daily.

\section{Comparing bleeps to WhatsApp}

Doctors were asked to what extent they agree with the following statement: "A group messaging service is more useful than a bleep". Twenty-two individuals (41.5\%) agreed with this statement with $16 / 53$ (30.5\%) disagreeing and $15(28.3 \%)$ remaining neutral. There was a statistically significant difference between the opinions of foundation doctors (who generally favoured WhatsApp) and senior trainees/ consultants (who generally favoured bleeps); $p=0.047$. Statistical significance was approached when comparing core trainee/SHO level to senior trainee/consultant ( $\mathrm{p}=0.057$ ) (Figure 1).

Responses to this question seemed to be partially related to the number of times doctors were bleeped during the day with a step wise increase in preference for use of a smartphone messaging service such as WhatsApp with increased frequency of bleeps received. Doctors bleeped $<5$ times per day scored a mean of $3.0 \pm 1.13$ (scored out of 5), doctors bleeped 5-10 times scored a mean of 3.07 \pm 1.16 and doctors bleeped $>10$ times scored a mean of $3.89 \pm 1.17$, although this did not reach statistical significance $(\mathrm{p}=0.143)$. Similarly, doctors unable to find a phone to return the bleep scored a mean of $3.29 \pm$ 1.24 compared to those able to find phones who scored a mean of $2.81 \pm 0.87$ ( $\mathrm{p}=0.245)$, offering some potential insight into reasons for preference of WhatsApp.

There was a statistically significant difference in scoring between doctors who used WhatsApp for work-related purposes $(3.46 \pm 1.14)$ and doctors who do not $(2.43 \pm 0.94) ; \mathrm{p}=0.004$. Statistical significance

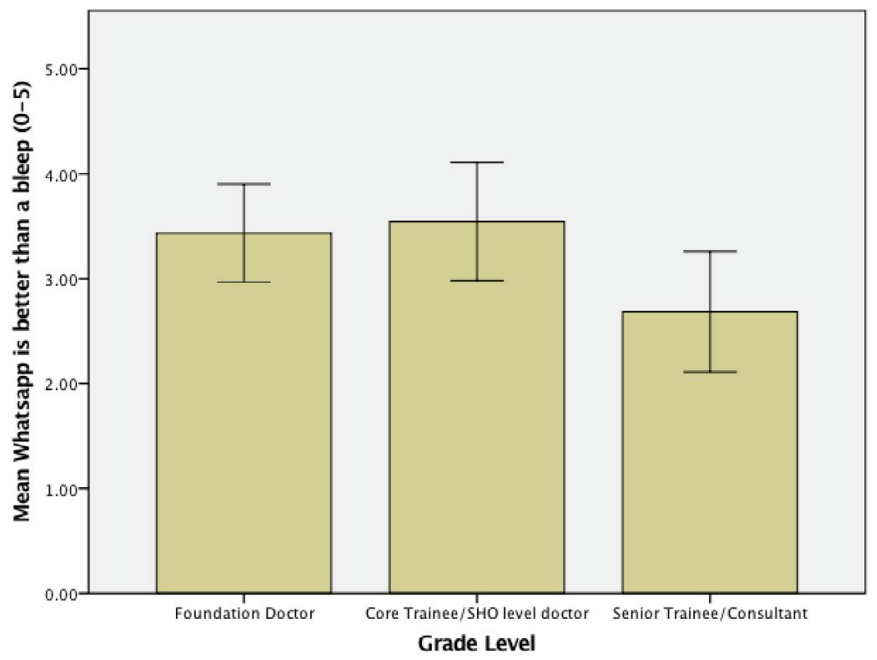

Figure 1. Bar chart demonstrating to what extent doctors agree with the following statement: "A group messaging service is more useful than a bleep" (1=strongly disagree, $2=$ disagree, $3=$ neutral, $4=$ agree, $5=$ strongly agree)

was also demonstrated for doctors who used WhatsApp for social purposes compared to those who did not ( $\mathrm{p}=0.005)$; for example, 'never' scored a mean of $2.40 \pm 0.83$ whilst 'more than once daily' scored a mean of $4.09 \pm 1.04$. Similarly, doctors who used WhatsApp for patient advice within their own team scored higher compared to those who did not $(p=0.001)$. Finally, a statistically significant difference mean score was observed between doctors who used WhatsApp to organise rota swaps and those who did not $(\mathrm{p}=0.007)$ as well as doctors who use WhatsApp to inform colleagues of illness compared to those who did $\operatorname{not}(\mathrm{p}=0.001)$.

\section{Free text responses}

Doctors were given the chance to write their own thoughts in free text comments at the end of the questionnaire. A number of themes emerged in response to both questions.

With regards to critiques of the bleep system, three main themes emerged. The first was that bleeps make being on-call much more chaotic; the bleeps are constantly sounding, and their usage requires a lot of time.

The second theme was that of general grievances with accessing bleep numbers through switchboards or online directories.

The third theme was day-to-day practical problems of bleep use, including not being able to find a phone to reply on, or finding the system was regularly engaged.

Other topics touched on in the free text section included the ease of messaging that WhatsApp facilitates - with comments about it being quicker, easier and with the benefit of providing acknowledgement of receipt of the message.

Patient confidentiality was raised as a reason for concern with use of smartphone messaging applications. Several respondents raised anxiety that if WhatsApp messages were ever hacked into and patient identifiable material found, patient confidentiality will have been compromised. This could have severe repercussions for the clinicians involved and their health boards, as well as damaging doctor-patient trust.

Some advantages of bleeps were raised in our free text section that could be taken account of if designing a system aimed to supersede 
bleeps. Firstly, it was noted that doctors appreciated the fact that they could not be bleeped outside of work, thus demarcating a clear boundary between work and social life in a way that a mobile phone application would not. Secondly, the intrusiveness of bleeps was raised as an advantage if trying to get hold of someone in an emergency (especially the 'fast bleep' facility). Thirdly, the superior battery life and extensive hospital cover of bleeps compared to poorer battery life and cellular/Wi-Fi dependent mobile phones. Finally, the superior confidentiality and professionalism of using a bleep as opposed to a mobile phone, which could be visually interpreted by patients and their relatives as slacking on the job.

\section{Discussion and Conclusion}

Doctors across all grades experience problems with the use of bleeps, which has led to an increase in the use of smartphone applications such as WhatsApp for work purposes.

There has been a number of publications in recent years that have shown a preference for smartphone-enabled communication software such as WhatsApp, particularly amongst surgical specialities $[5,6]$. The use of applications like WhatsApp have allowed for speedier communication amongst team members but comes with the caveat of concerns about security of data and the need to anonymise patient information [7].

Here we not only evaluated patterns of WhatsApp use amongst doctors in a single centre but also for the first time attempted to identify particular reasons for preference of use whilst still having access to a bleep system to communicate through.

Our data demonstrates that it is not uncommon for doctors to receive no answer to their bleeps, i.e. on receiving a bleep call, the caller often leaves the phone before receiving the call back. In the free text comments, we established that this caused some angst for doctors who are trying to prioritise tasks but are unaware of the nature and potential severity of any calls received. Whilst smartphone messaging applications such as WhatsApp do not guarantee a reply either, there is no requirement to sit at a phone waiting for the recipient to call back. This time was judged as being useful as it could potentially be used to perform other tasks and deprives other team members of the phone who may want to use it. Indeed, if other team members are timepressed they will use the phone anyway, which leads to our next finding; namely that it was not uncommon for doctors, upon answering a bleep, to find that the phone is engaged.

Perhaps as a consequence of the above problems, the majority of doctors replying to our survey acknowledged to usage of WhatsApp to communicate whilst at work even though they already had a bleep system to communicate with. The greatest work-related use of WhatsApp was for patient advice within the doctors' own teams. Organising rota swaps and informing team members of illness was also regularly undertaken. Seeking of patient advice outside the doctors' teams was less commonly performed.

A number of interesting observations were made about patterns for WhatsApp use, in particular that foundation doctors had different experiences with bleeps and different perceptions of WhatsApp compared to other grades of doctors.

Our study revealed that foundation doctors experience the most issues with bleeps. They had the most trouble with experiencing no answers to their bleeps (statistically significant when compared to other grades). They had the most trouble with finding the phone to be engaged and they also had the most trouble with being unable to find a phone in which to answer a bleep (statistically significant when compared to senior trainees/consultants).

There are many potential explanations for these findings. One is that people bleeping senior doctors are aware of the hierarchical structure within the NHS and will take greater care not to abandon call these doctors. Another is that senior doctors often have more managerial and administrative work which whilst equally as time consuming as ward-based/clinical work is easier to pause in order to respond to a bleep than in the case of a junior doctor who is engaged in a clinical activity which they cannot immediately leave. It is also plausible that junior team members receive more calls for perceived simpler tasks and hence a higher frequency of bleep calls will always allow for an increased potential for difficulty in answering.

Overall, the majority of doctors included in this study were users of WhatsApp, especially foundation doctors. When comparing foundation doctors to other grades with regards to organising rota swaps with WhatsApp, a significant proportion used WhatsApp for such purposes. The increased social and medical uses of WhatsApp amongst the more junior doctors perhaps demonstrates the cultural shift associated with technological use. With time, it is inevitable that such forms of communication amongst medical professionals will continue increasing, even if it is not recommended.

Foundation doctors also agreed more strongly that group messaging services are more useful than bleeps; this exhibited statistical significance when comparing their opinions with senior trainees/ consultants.

Doctors bleeped most frequently were more likely to use WhatsApp, $\mathrm{p}=0.007$ (Chi Square) and those who were unable to find phones to return bleeps were also statistically more likely to use WhatsApp for patient advice within their own team. Furthermore, doctors whose bleeps sounded at inappropriate times were statistically more likely to use WhatsApp for this purpose, $\mathrm{p}=0.026$ (Chi Square).

These data support the assumption that foundation doctors use WhatsApp more at least partly because they experience the greatest issues with bleeps.

The use of smartphone applications as superior messaging alternatives to bleeps is highly contentious. The GMC, the public body that maintains the official register of medical practitioners within the United Kingdom, advises doctors against its use due to perceived notions that patient confidentiality may be compromised if the data is hacked [9]. Whilst doctors using WhatsApp strive to maintain confidentiality through use of patient abbreviations (e.g. JH) and removing patientidentifiable information, slips do invariably occur. Our free-text responses demonstrated that this was one of the main disadvantages' doctors thought of with group messaging services such as WhatsApp. When discussing patients' clinical details over WhatsApp, the patient's permission has not been sought, the transmission is irreversible and further usage of information by the intended (or unintended) recipients is out of control of the original sender [10].

We acknowledge some limitations with our study. Firstly, the questionnaire comprised of self-reported data and is therefore open to bias by those that hold extreme views on either end of the argument. Secondly, our interpretation of some of the results is limited as we do not have exact data on average time taken to respond to calls and hence are open to an element of respondent recall bias. Some of the questions are also broad such as whether doctors prefer WhatsApp or 
bleeps - it may be that different scenarios require different needs (e.g. urgent vs. non-urgent queries) but we felt that asking more questions would have resulted in survey fatigue which would have undoubtedly further reduced an already low response rate. Thirdly, with a modest response rate, we acknowledge that firm conclusions cannot be made. That said, we have reported on the well-known fact that in spite of GMC recommendations, use of smartphone applications to communicate is still ongoing. We also for the first time have attempted to unpick some of the reasons behind a preference for software such as WhatsApp, in particular identifying reasons why bleep use is met with adversity. Fourthly, we did not have a group of 'pure bleep' users to interrogate. This would have added value to the study but would have been difficult to achieve given that most individuals carry smartphones with messaging technology. Finally, we have not investigated the usage of WhatsApp amongst other healthcare professionals nor considered how inter-professional communication would work with WhatsApp in this manner. Whilst the focus of the study was to compare WhatsApp to bleeps amongst medical staff, who are the main holders of bleeps, considering other healthcare professionals would have been an interesting angle.

Whilst this study focussed on WhatsApp due to its unrivalled popularity, we acknowledge that other software may be used by other doctors in different hospitals. For example, Digital Enhanced Cordless Technology (DECT) phones, which may be a means of negating some of the concerns regarding patient confidentiality and work/social life separation. As far as we are aware, there have been no studies looking at DECT use within a medical context. Additionally, one must note that not all of these phones have messaging capabilities which are especially useful in non-urgent queries where the intended recipient can reply at their leisure rather than being consistently interrupted during ward duties. Nevertheless, future research comparing these to mobile applications such as WhatsApp would be of great value.

There can be no doubt that internet enhanced technology will continue to develop and play an essential role in healthcare settings [11] with the potential to improve communication and patient outcomes. Bleeps are widely disliked amongst medical professionals who are increasingly using social messaging platforms such as WhatsApp to facilitate easier communication. Unless a solution is implemented to address the shortfalls of bleeps, the usage of messaging platforms such as WhatsApp will continue to increase regardless of guidance advising against it.

We do not believe the solution lies in these applications, which despite their advantages are seriously concerning. Main concerns include patient confidentiality, which has the potential to erode doctorpatient trust, as well as work/social life boundaries, which could have negative effects on the wellbeing of staff. We suggest a hospital-regulated portable telephone system that allows two-way communication via calls and texts. This would be more practical than mobile phones for those who do not have smartphones, do not have extensive data plans, do not check their phones regularly or keep their phones on silent. It would also prevent work-related messages and calls from encroaching on the social lives of doctors, since these would be left in the hospital.

Future research could focus on the usage of WhatsApp amongst other healthcare professionals to determine if they hold views similar to those demonstrated in this study. It could also aim to further dissect whether there are any specific scenarios in which bleep use or WhatsApp use is preferred - for example, in the event of an urgent query is a doctor more likely to use a bleep or phone call/message e.g. via WhatsApp. Studies could also be performed in hospitals where the bleep system is not the primary system of communication; these hospitals may use DECT phones or similar. Whilst on the surface such devices seem appealing, perhaps grievances also exist with their use too. All of this research could then be pooled together to design a communication system superior to bleeps, that considers patient confidentiality, ease of use and the separation of work/social life.

\section{References}

1. Wilmer HH, Sherman LE, Chein JM (2017) Smartphones and cognition: A review of research exploring the links between mobile technology habits and cognitive functioning. Front Psychol 8: 605.

2. Ozdalga E, Ozdalga A, Ahuja N (2012) The smartphone in medicine: a review of current and potential use among physicians and students. J Med Internet Res 14: e128.

3. Haroon M, Yasin F, Eckel R, Walker F (2010) Perceptions and attitudes of hospital staff toward paging system and the use of mobile phones. Int $J$ Technol Assess Health Care 26: 377-381.

4. Martin G, Janardhanan P, Withers T, Gupta S (2016) Mobile revolution: a requiem for bleeps? Postgrad Med J 92: 493-496.

5. Firdouse M, Devon K, Kayssi A, Goldfarb J, Rossos P (2018) Using texting for clinical communication in surgery: A survey of academic staff surgeons. Surg Innov 25: 274 279

6. Kameda-Smith MM, Iorio-Morin C, Winkler-Schwartz A, Ahmed US, Bergeron D, et al. (2018) Smartphone usage patterns by canadian neurosurgery residents: A national cross-sectional survey. World Neurosurg 111: e465-e470.

7. El Hadidy TS, Alshafei AE, Mortell AE, Doherty EM (2018) Smartphones in clinical practice: doctors' experience at two Dublin paediatric teaching hospitals. Ir J Med Sci 187: $565-573$.

8. Giordano V, Koch H, Godoy-Santos A, Belangero WD, Santos Pires RE, et al. (2017) WhatsApp messenger as an adjunctive tool for telemedicine: An overview. Interact $J$ Med Res 6: e11.

9. General Medical Council (2013) Doctors' use of social media. London: GMC.

10. Natarajan S, Nair AG (2015) Outsmarted by the smartphone! Indian J Ophthalmol 63 : 757-758.

11. Barr NG, Randall GE, Archer NP, Musson DM (2017) Physician communication via Internet-enabled technology: A systematic review. Health Informatics $J 1$ : 1460458217733122

Copyright: (C2019 Abdullah A. This is an open-access article distributed under the terms of the Creative Commons Attribution License, which permits unrestricted use, distribution, and reproduction in any medium, provided the original author and source are credited. 